\title{
Surgical Correction of Bifid Nose Due to Tessier's No. 0 Cleft
}

\author{
Hiroki Shibayama ${ }^{1}$, Takatoshi Yotsuyanagi ${ }^{2}$, Tamotsu Saito ${ }^{2}$, Ken Yamashita², Makoto Yamauchi ${ }^{2}$, \\ Tetsuya Suda ${ }^{3}$
}

\begin{abstract}
${ }^{1}$ Department of Plastic and Reconstructive Surgery, Fujisawa City Hospital, Kanagawa, Japan; ${ }^{2}$ Department of Plastic and Reconstructive Surgery, Sapporo Medical University School of Medicine, Hokkaido, Japan; ${ }^{3}$ Department of Plastic and Reconstructive Surgery, Sunagawa City Medical Center, Hokkaido, Japan.

Email: hiroki2001com@yahoo.co.jp
\end{abstract}

Received October $18^{\text {th }}, 2013$; revised November $15^{\text {th }}$, 2013; accepted November $23^{\text {rd }}, 2013$

Copyright (C) 2014 Hiroki Shibayama et al. This is an open access article distributed under the Creative Commons Attribution License, which permits unrestricted use, distribution, and reproduction in any medium, provided the original work is properly cited. In accordance of the Creative Commons Attribution License all Copyrights @ 2014 are reserved for SCIRP and the owner of the intellectual property Hiroki Shibayama et al. All Copyright (C) 2014 are guarded by law and by SCIRP as a guardian.

\section{ABSTRACT}

Bifid nose is a rare congenital abnormality and its surgical correction is difficult. We represent a case of bifid nose with mild nasal deformity without cerebral or lip deformity. We performed rhinoplasty with a kind of the forked flap at one year of age and the appearance improved.

\section{KEYWORDS}

Bifid Nose; Rhinoplasty; Forked Flap; Tessier's No. 0 Cleft

\section{Introduction}

Bifid nose is one of the features of Tessier's No. 0 or No. 14 craniofacial clefts [1], and is caused by the failure of the medial and lateral nasal processes to achieve contact with each other during the first eight weeks of fetal life. There are few reports of the surgical correction of bifid nose, and we describe here our experience of bifid nose due to Tessier's No. 0 cleft. We performed rhinoplasty with a type of the forked flap [2] at one year one month of age and achieved relatively good results.

\section{Case Report}

A one-month-old boy presented with congenital nasal disfigurement and a subcutaneous tumor on the dorsum of the nose. He had no anomalies of other organs, and his delivery was normal. His close relatives had no congenital anomaly. Grooving of the nasal tip and columella was observed. His nose was relatively short. The width of the columella was increased and the distance between the nostrils was long. Canthal index was 47. There was an elastic soft subcutaneous tumor on the dorsum of the nose. Median cleft lip, cleft palate and duplicated labial frenulum were not present (Figure 1). Computed-tomo- graphy revealed that the nasal bone was flattened but the nasal septum was normal. No central nervous system anomalies such as cranium bifidum or a frontonasal encephalocele were recognized. The tumor was suspected to be a lipoma (Figure 2).

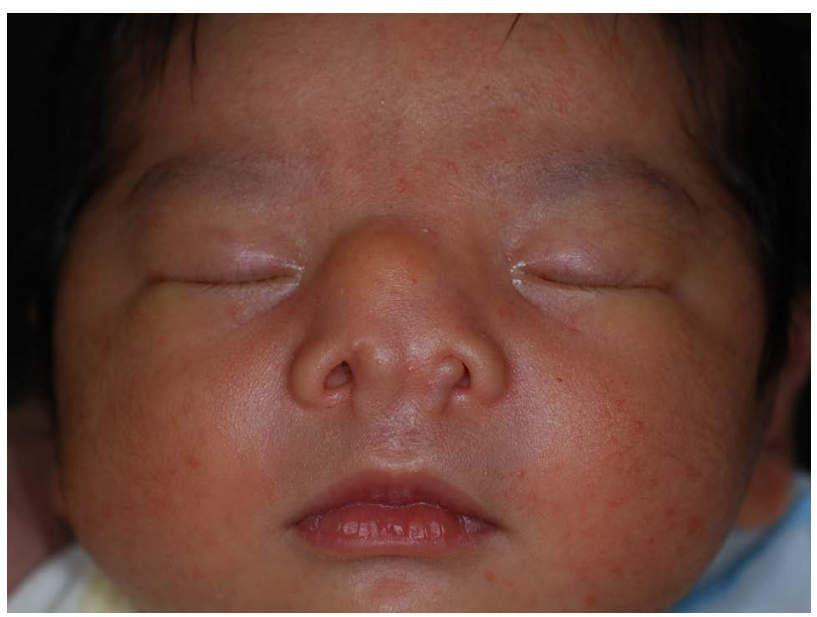

Figure 1. First visit to our hospital. There is a groove at the nasal tip and the dorsum of the nose and the columella were wide. 
We perfomed rhinoplasty and tumor excision at one year one month of age under general anesthesia. The design was similar to a forked flap, to elevate the nasal tip (Figures 3 and 4). After elevation of the columella, we found that the anterior nasal spine was wide and both alar cartilages were displaced laterally (Figure 5). The cartilages were moved medially and sutured to each other after excision of redundant subcutaneous tissue, then the flap forming the philtrum was fixed. Lastly, the flaps forming the columella were trimmed and sutured (Figures 6 and 7). Pathological examination of subcutaneous tissue showed lipoma, with no malignancy. Six months after the operation, the appearance of his nose was relatively improved and all scars were inconspicuous (Figures 8 and 9).

\section{Discussion}

Bifid nose has been called by several names for a long time. In 1889, Trendelenburg [3] was described this findings as "Doggennase", and this is recognized as the first report about bifid nose. In 1910 Wilkinson [4] firstly used the term "bifid nose". In 1967 DeMyer [5] sug-

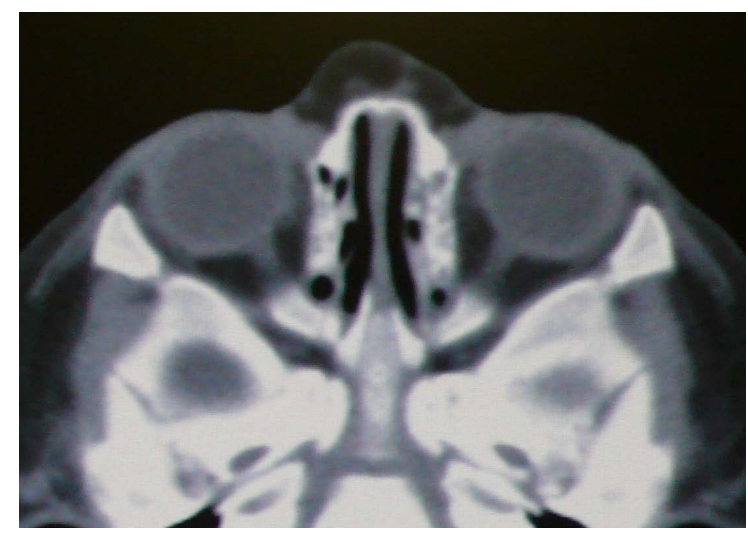

Figure 2. Computed-tomography showed the flattened nasal bone, however the nasal septum was normal.

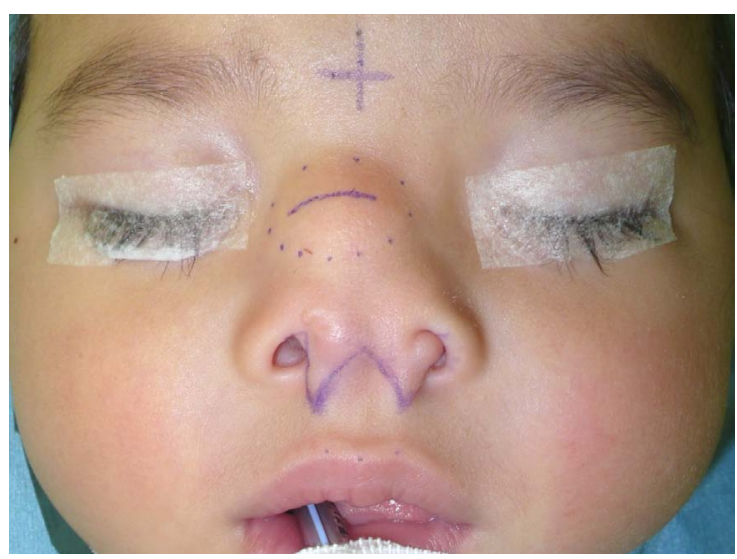

Figure 3. Design: We performed rhinoplasty with a kind of “forked flap".

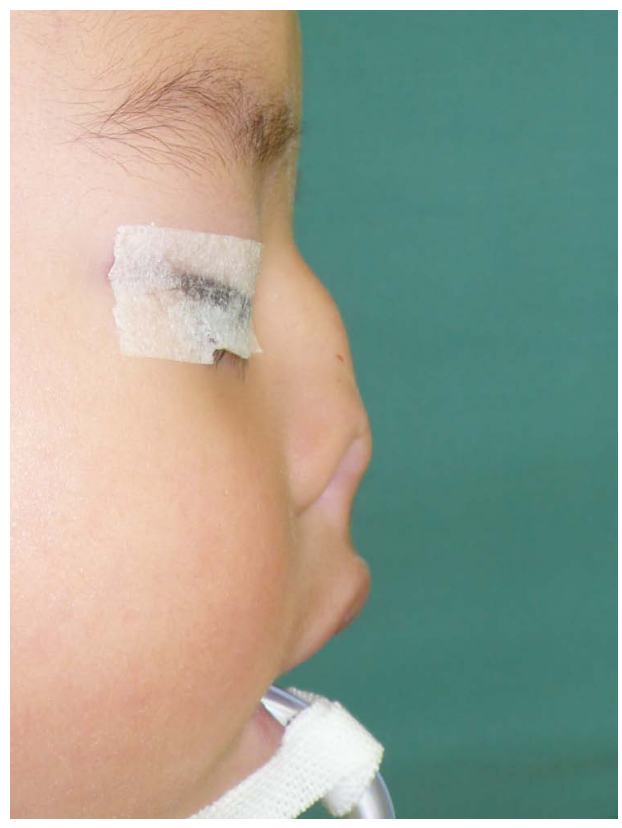

Figure 4. Lateral view before surgery.

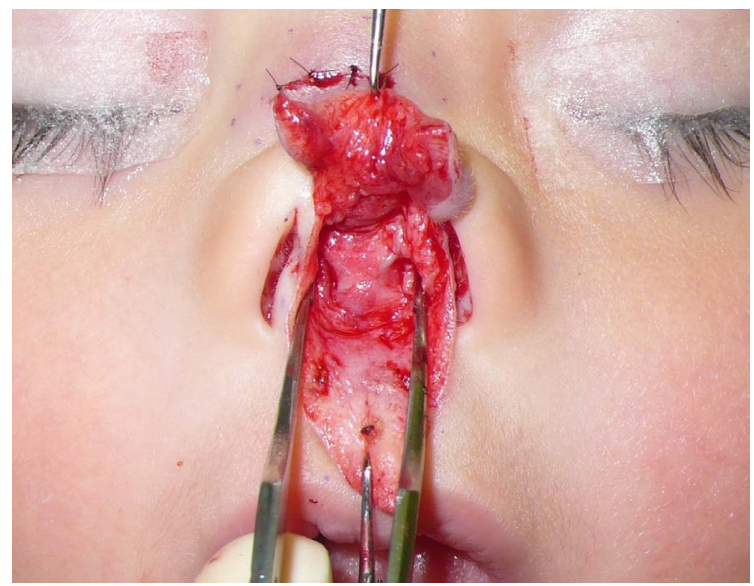

Figure 5. The anterior nasal spine was wide and the alar cartilages were separated. There was redundant tissue between the cartilages.

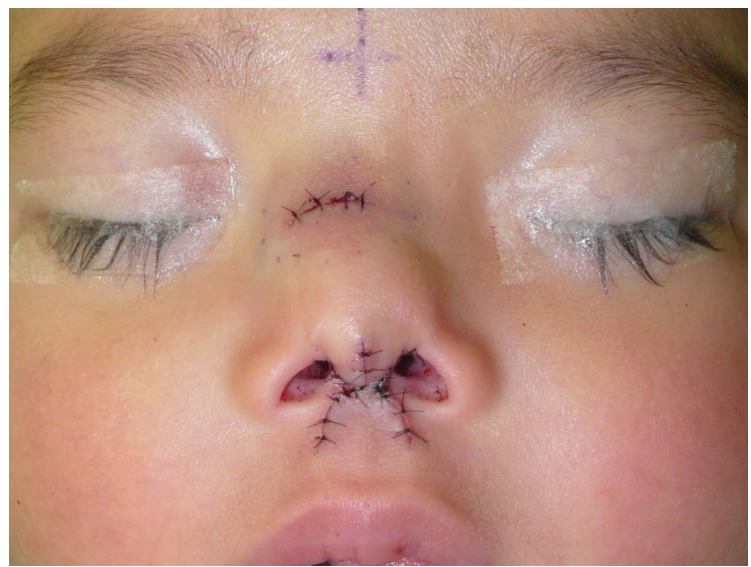

Figure 6. Immediately after the surgery: Front view. 


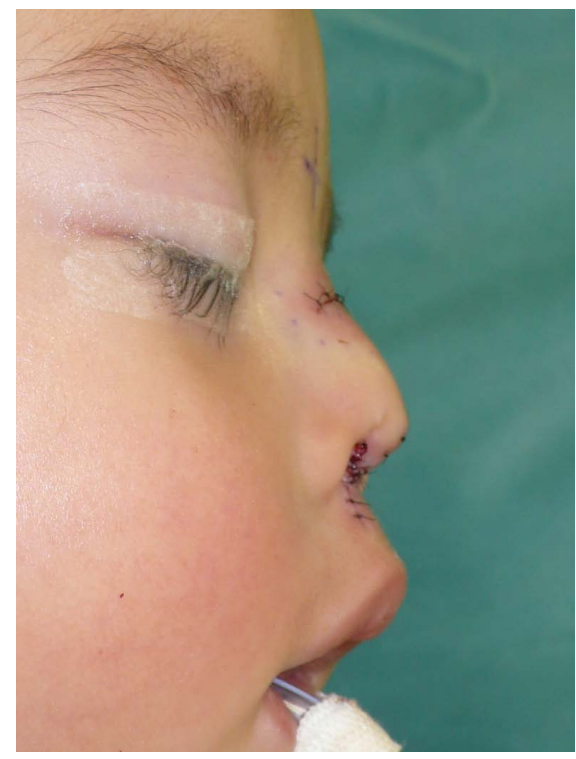

Figure 7. Immediately after the surgery: Lateral view.

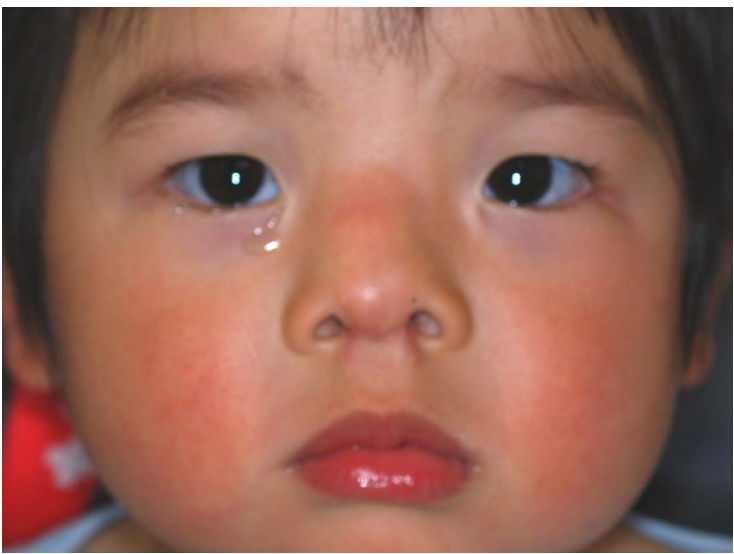

Figure 8. Six months after the surgery: Front view.

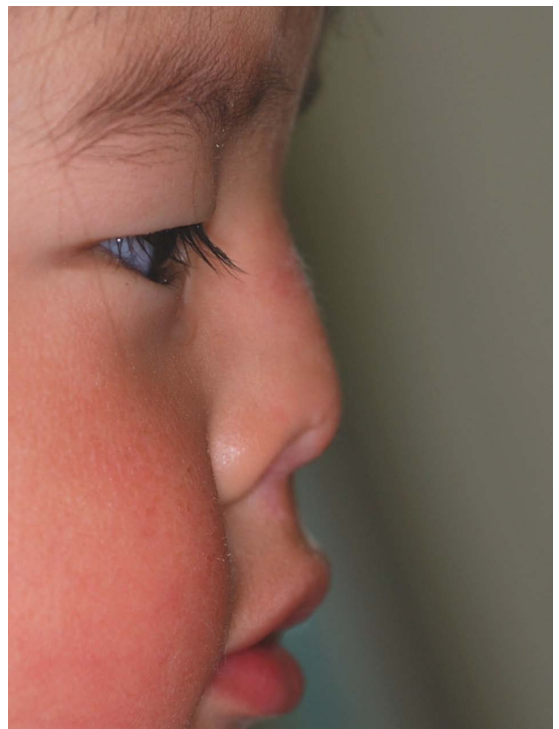

Figure 9. Six months after the surgery: Lateral view. gested "median cleft face syndrome" for congenital deformities of the medial area of the face. However Sedano [6] rejected this suggestion because DeMyer's definition was inadequate, and presented a new concept, "frontonasal dysplasia". After that, the concept of congenital deformities of the medial area of the face became complicated. In 1976 Tessier reported a classification of craniofacial cleft, and now, this classification is most widely accepted. In the classification, bifid nose is associated with No. 0 and No. 14 clefts.

The cause of bifid nose is known to be the failure of the medial and lateral nasal processes to achieve contact with each other during the first eight weeks of fetal life. Many theories and states such as central disorganization of the neural crest, external pressure, oligohydramnios, amniotic bands, and hematoma have been proposed as etiological mechanisms of this congenital anomaly.

Tessier's No. 0 or No. 14 cleft often presents with bifid nose, median cleft lip and hypertelorism. The degree of disease is varies in each patient, and the associated brain malformation generally limits the life span to infancy. There are some reports of associated congenital anomalies of other than the face, but their relationship with these clefts is unclear [7]. In bifid nose, some vertical skin grooves are generally observed in the nasal tip or dorsum and lower nasal tip. The dorsum and root of the nose are broad and flattened. The alar and lateral cartilages are displaced laterally, and the nasal bone and septum become separated or thick. In No. 0 cleft, the manifestations are deformities of the nose and nasal septum. This cleft is often associated with median cleft lip and cleft palate, and some authors have reported patients with lipoma, epidermoid cyst and teratoma [8]. The manifestations of No. 14 are deformities of the orbit, and associated brain or cranial deformities such as holoprosencephaly or microcephaly are often found. In the present case, the patient presented with nasal deformities, hypertelorism and lipoma without brain or cranial deformity, and we considered this to be Tessier's No. 0 cleft.

The treatment of bifid nose was first reported by Joseph [9] in 1931, who described composite grafting for mild cases, a VY advancement flap for moderate cases, and a forehead flap with free bone grafting for severe cases. For mild or moderate cases, some authors suggested modifications of Joseph's technique. In 1949 Webster [10] described osteotomy of the widened nasal bone and maxilla, and he replaced the nasal cartilage medially by suturing them to each other. After bone and/or cartilage surgery, soft tissue reconstruction was performed, such as excision of the redundant skin or $\mathrm{V}-\mathrm{Y}$ plasty. In 1958 Peer [11] reported suture of the alar cartilages for mild cases. In 1987 Ortiz [12] suggested active osteotomy in 59 cases in which the patient had a bony cleft. However, in 2005 Tayfun [13] stated that 
active ostetomy should not be perfomed, in order to avoid an adverse effect on nasal growth.

In this case we planned replacement of the alar cartilages and designed a forked flap to narrow the columella and heighten the nasal tip because the nasal deformity was mild. After incision, we removed the redundant soft tissue between the alar cartilages, and then sutured them to each other. In view of the patient's age, we did not perform osteotomy or cartilage grafting. Although the timing of surgery is controversial, we think it should not be performed before one year of age in consideration of the risk of general anesthesia.

\section{Conclusion}

We performed rhinoplasty with a type of forked flap for bifid nose patient at one year one month of age and achieved relatively good results. Patients with bifid nose are classified into No.0 or 14 cleft by Tessier's classification and we should plan a surgery for each patient individually because nasal malformations are different in each case.

\section{REFERENCES}

[1] P. Tessier, "Anatomical Classification of Facial, Craniofacial and Laterofacial Clefts," Journal of Maxillofacial Surgery, Vol. 4, 1976, pp. 69-81.

http://dx.doi.org/10.1097/00006534-195811000-00004

[2] D. R. Millard, "Columella Lengthening by a Forked Flap," Plastic \& Reconstructive Surgery \& the Transplantation Bulletin, Vol. 22, No. 5, 1958, pp. 454-457. http://dx.doi.org/10.1097/00006534-195811000-00004

[3] H. Trendelenburg, "Deutsche Chirurgie (Billroth and Luecke),” Lief, 1886.

[4] G. Wilkinson, “A Case of Bifid Nose,” Journal of La- ryngology \& Otology, Vol. 37, No. 11, 1922, pp. 560-563. http://dx.doi.org/10.1017/S0022215100023938

[5] D. William, “The Median Cleft Face Syndrome,” Neurology, Vol. 17, 1967, pp. 961-971. http://dx.doi.org/10.1212/WNL.17.10.961

[6] H. O. Sedano, M. M. Cohen, J. Jan, et al., "Frontanasal Dysplasia,” Journal of Pediatrics, Vol. 76, No. 6, 1970, pp. 906-913.

http://dx.doi.org/10.1097/SCS.0b013e31818c0768

[7] C. Patrick, K. Yoav and H. Larry, "Bifid Nose with Cleft Hand Deformity: Syndromic Association or Undescribed Anomaly?” Journal of Craniofacial Surgery, Vol. 19, No. 6, 2008, pp. 1594-1596. http://dx.doi.org/10.1097/SCS.0b013e31818c0768

[8] R. da Silva Freitas, N. Alonso, J. H. Shin, L. Busato, M. C. Ono and G. A. Cruz, "Surgical Correction of Tessier Number 0 Cleft," Journal of Craniofacial Surgery, Vol. 19, No. 5, 2008, pp. 1348-1352.

[9] J. Joseph, “Doggennasenplastik," In: Nasenplastik und Sonstige Gesichtplastik, Kabitzsch, Leipzig, 1931, pp. 476-485.

[10] J. P. Webster and E. Denning, "Surgical Treatment of the Bifid Nose," Plastic and Reconstructive Surgery, Vol. 6, No. 1, 1950, pp. 1-37. http://dx.doi.org/10.1097/00006534-195007000-00001

[11] L. A. Peer and J. C. Walker Jr., "New instruments for Rhinoplasty," Plastic and Reconstructive Surgery, Vol. 10, No. 5, 1952, pp. 372-374. http://dx.doi.org/10.1097/00006534-195211000-00007

[12] M. F. Ortiz, C. A. Fuente del, et al., "Nasal Clefts,” Annals of Plastic Surgery, Vol. 18, No. 5, 1987, pp. 377-397. http://dx.doi.org/10.1097/00000637-198705000-00004

[13] T. Tayfun, O. Hakan, G. Bulent and O. Zafer, "Combined Intraoral and Nasal Approach to Tessier No: 0 Cleft with Bifid Nose,” Annals of Plastic Surgery, Vol. 54, No. 2, 2005, pp. 207-210.

http://dx.doi.org/10.1097/01.sap.0000132886.09553.21 